\title{
Adsorptive Removal of Copper by Using Surfactant Modified Laterite Soil
}

\author{
Tien Duc Pham, ${ }^{1}$ Hoang Hiep Nguyen, ${ }^{1}$ Ngoc Viet Nguyen, ${ }^{1}$ Thanh Tu Vu, \\ Thi Ngoc Mai Pham, ${ }^{1}$ Thi Hai Yen Doan, ${ }^{1}$ Manh Ha Nguyen, ${ }^{1}$ and Thi Mai Viet Ngo ${ }^{2}$ \\ ${ }^{1}$ Faculty of Chemistry, VNU-University of Science, Vietnam National University-Hanoi, 19 Le Thanh Tong, Hoan Kiem, \\ Hanoi 10000, Vietnam \\ ${ }^{2}$ Thai Nguyen University of Education, Thai Nguyen University, 20 Luong Ngoc Quyen, Quang Trung, Thai Nguyen, Vietnam
}

Correspondence should be addressed to Tien Duc Pham; tienduchphn@gmail.com

Received 29 December 2016; Accepted 13 February 2017; Published 2 March 2017

Academic Editor: Khalid Z. Elwakeel

Copyright (C) 2017 Tien Duc Pham et al. This is an open access article distributed under the Creative Commons Attribution License, which permits unrestricted use, distribution, and reproduction in any medium, provided the original work is properly cited.

\begin{abstract}
Removal of copper ion $\left(\mathrm{Cu}^{2+}\right)$ by using surfactant modified laterite (SML) was investigated in the present study. Characterizations of laterite were examined by X-ray diffraction (XRD), Fourier transform infrared spectroscopy (FT-IR), inductively coupled plasma mass spectrometry (ICP-MS), and total carbon analysis. The optimum conditions for removal of $\mathrm{Cu}^{2+}$ by adsorption using SML were systematically studied and found as $\mathrm{pH}$ 6, contact time $90 \mathrm{~min}$, adsorbent dosage $5 \mathrm{mg} / \mathrm{mL}$, and ionic strength $10 \mathrm{mM} \mathrm{NaCl}$. The equilibrium concentration of copper ions was measured by flame atomic absorption spectrometry (F-AAS). Surface modification of laterite by anionic surfactant sodium dodecyl sulfate (SDS) induced a significant increase of the removal efficiency of $\mathrm{Cu}^{2+}$. The surface modifications of laterite by preadsorption of SDS and sequential adsorption of $\mathrm{Cu}^{2+}$ were also evaluated by XRD and FT-IR. The adsorption of $\mathrm{Cu}^{2+}$ onto SML increases with increasing $\mathrm{NaCl}$ concentration from 1 to $10 \mathrm{mM}$, but at high salt concentration this trend is reversed because desorption of SDS from laterite surface was enhanced by increasing salt concentration. Experimental results of $\mathrm{Cu}^{2+} / \mathrm{SML}$ adsorption isotherms at different ionic strengths can be represented well by a two-step adsorption model. Based on adsorption isotherms, surface charge effects, and surface modification, we suggest that the adsorption mechanism of $\mathrm{Cu}^{2+}$ onto SML was induced by electrostatic attraction between $\mathrm{Cu}^{2+}$ and the negatively charged SML surface and nonelectrostatic interactions between $\mathrm{Cu}^{2+}$ and organic substances in the laterite.
\end{abstract}

\section{Introduction}

Removal of heavy metal ion from aqueous solution is important in environmental concern because heavy metal can induce serious problems to human health through the water resources. Therefore, so many projects focus on the removal of heavy metal ion to protect water resources [1-7]. Numerous treatment techniques have been used for heavy metal ion removal from the aquatic environment such as adsorption, ion exchange, coagulation/flocculation, chemical precipitation, photodegradation, and electrochemical oxidation [8-11]. Among these techniques, adsorption is one of the most common technologies for removing heavy metal ions $[8,10,12-15]$. Although activated carbon and activated metal oxides are effective adsorbent for the removal of heavy metal ions [2, 4, 14-17], a big challenge is costly. Thus, cheap adsorbents or/and natural adsorbents or modified cheap adsorbents are preferable in developing countries $[5,8,12$, 18]. To increase the removal efficiency of heavy metal ion by natural minerals, a modification of adsorbent surfaces is needed because the surface of such materials is nonactive. The modified solid adsorbents to remove metal ion was successfully investigated by many researches and,in these cases, not only adsorption capacity but also the adsorptive selectivity was significantly enhanced [19-21].

Copper, which is well-known heavy metal, is toxic and nonbiodegradable to aquatic ecosystems and living organisms [22]. Therefore, copper can accumulate in sediments and tissues of living organisms, and separation of copper ions is essential to discharge wastewater into environment. Recently, many studies investigated the removal of copper ion, $\mathrm{Cu}(\mathrm{II})$, by adsorption techniques using novel adsorbent 
$[3,16,22-25]$. Adsorptive removal of $\mathrm{Cu}(\mathrm{II})$ by chemically modified adsorbent was investigated in previous studies [3, 26].

Laterite is a common soil in tropical countries. Laterite is also easily collected in Vietnam, meaning that laterite is very low cost. Basically, laterite has positive charge in the acid and neutral media so it has been widely used for the removal of many toxic anionic ions including anionic heavy metal $[5,27,28]$. Nevertheless, the removal of cations is rather hard due to the strong electrostatic repulsive force. Thus, in order to increase the removal efficiency of the heavy metal cations by adsorption technique, surface modification of laterite is necessary. Anionic surfactant such as sodium dodecyl sulfate (SDS) is an ecofriendly chemical that can be used in environmental remediation to remove both inorganic and organic pollutants [29]. However, SDS modified laterite to remove $\mathrm{Cu}^{2+}$ has not been studied [5].

Adsorption is normally conducted under isothermal condition so that adsorption isotherms fitted by theoretical models are useful to better understand adsorption mechanisms and to explain the interactions between the laterite and copper ion. As for describing adsorption characteristics of heavy metal ions, Langmuir and Freundlich isotherm models are often discussed [30, 31]. However, Langmuir and Freundlich models cannot be applied for adsorption isotherms of surfactants. Thus, adsorption of inorganic pollutants onto surfactant modified laterite could not be fitted by Langmuir and Freundlich models. Fortunately, a twostep model presented by Zhu and $\mathrm{Gu}$ [32] with a general adsorption isotherm equation was successfully applied to various types of surfactants, polymers, and dyes adsorption isotherms for numerous systems [32-37]. Adsorptive removal of both organic and inorganic pollutants by using surfactant modified alumina was thoroughly studied by Pal and coworkers $[2,16,38-41]$, indicating that surfactant modified solid adsorbent is a novel adsorbent. Nevertheless, the authors have not studied adsorption of $\mathrm{Cu}$ (II) on surfactant modified laterite.

In this study, we investigate adsorptive removal copper ion using surfactant modified laterite (SML). To the best of our knowledge, this is the first systematic study on the adsorption of copper ion from aqueous solution on SML. Characterizations of laterite and SML were determined by $\mathrm{X}$-ray diffraction (XRD), inductively coupled plasma mass spectrometry (ICP-MS), Fourier transform infrared spectroscopy (FT-IR), and total carbon analysis. The optimum parameters for adsorptive removal copper ion by using SML are systematically studied. The surface modification before and after adsorption is also investigated by XRD and FT-IR. The adsorption mechanism is also proposed on the basis of adsorption isotherms and surface modification.

\section{Experimental}

2.1. Materials. Raw laterite was collected from a local place of Thach That, Hanoi, Vietnam. The laterite was treated before measurements as follows: the laterite was washed various times by ultrapure water to reach neutral $\mathrm{pH}$ and then dried at $110^{\circ} \mathrm{C}$. The treated laterite was cooled in a desiccator at room temperature and stored in a polyethylene container. The dried laterite was sieved in order to collect the particles with the size lower than $0.1 \mathrm{~mm}$. The laterite which was modified with $0.01 \mathrm{M}$ SDS (solid/liquid ratio $200 \mathrm{mg} / \mathrm{mL}$ ) in $0.01 \mathrm{M} \mathrm{NaCl}$ at $\mathrm{pH} 4$ by shaking for $3 \mathrm{~h}$ and then washed with ultrapure water was called surfactant modified laterite (SML).

Standard solution of copper (1000 ppm in $0.5 \mathrm{M} \mathrm{HNO}_{3}$ ) was supplied by Merck (Germany). All chemicals were of analytical reagent grade and were used without further purification. Copper nitrate salt, $\mathrm{Cu}\left(\mathrm{NO}_{3}\right)_{2} \cdot 3 \mathrm{H}_{2} \mathrm{O}$, was purchased from Merck (Germany). Anionic surfactant, sodium dodecyl sulfate (SDS, with purity $>95 \%$ ), from Scharlau (Spain, EU), was used to modify the surface of laterite. The effect of ionic strength was studied by the addition of $\mathrm{NaCl}$ (Merck). In order to adjust solution $\mathrm{pH}, \mathrm{HCl}$, and $\mathrm{NaOH}$ (Merck) were used. Ultrapure water system (Labconco, USA) with resistivity $18.2 \mathrm{M} \Omega$ was used to produce ultrapure water in preparing all aqueous solutions.

2.2. Adsorption Studies. All adsorption experiments were conducted by batch technique. Initially, the copper stock solution of $2000 \mathrm{ppm}$ was prepared by dissolving precisely calculated amount of copper nitrate salt. Then, the stock solution was appropriately diluted based on experimental requirement.

A known amount of adsorbents solution was thoroughly mixed with $50 \mathrm{~mL}$ aqueous copper solution $\left(\mathrm{Cu}^{2+}\right)$ of $10 \mathrm{ppm}$ in $250 \mathrm{~mL}$ Erlenmeyer flasks at $25 \pm 2^{\circ} \mathrm{C}$ controlled by an air conditioner. The effect of operating condition $(\mathrm{pH}$, adsorbent dosages, contact time, ionic strength, and initial absorbate concentration) on removal of $\mathrm{Cu}^{2+}$ was studied. The concentration of $\mathrm{Cu}^{2+}$ was determined by flame atomic absorption spectrometry (F-AAS). The removal $(R, \%)$ of $\mathrm{Cu}^{2+}$ was calculated by

$$
\operatorname{Removal}(R, \%)=\frac{C_{i}-C_{f}}{C_{i}} \times 100 \%
$$

where $C_{i}$ and $C_{f}$ are initial concentration and final concentration of $\mathrm{Cu}^{2+}$, respectively.

To study adsorption isotherms, the concentration of $\mathrm{Cu}^{2+}$ was varied from $10 \mathrm{ppm}$ to $2000 \mathrm{ppm}$ and $\mathrm{pH}$ was adjusted to the desired value. The adsorption capacity of $\mathrm{Cu}^{2+}\left(\Gamma \mathrm{Cu}^{2+}\right)$ onto SDS modified laterite was determined by the different concentrations of $\mathrm{Cu}^{2+}$ solutions before adsorption and after equilibrium process by F-AAS.

2.3. Instrumental Analytical Methods. The concentration of $\mathrm{Cu}^{2+}$ was determined by using an atomic absorption spectrometer (AA-6800, Shimadzu, Japan). Hollow cathode lamp $(\mathrm{HCL})$ was used to emit a narrow wavelength of $324.8 \mathrm{~nm}$. The slit width was kept as constant of $0.5 \mathrm{~nm}$ for all AAS measurements. The linear relationship between the absorbance and concentrations of $\mathrm{Cu}^{2+}$ had a correlation coefficient of at least 0.999 .

Concentration of anionic surfactant, SDS used for surface modification of laterite, was determined by spectrophotometry with Ultraviolet Visible spectrophotometer (UV-1650 PC, Shimadzu, Japan) followed our previous paper [36]. 


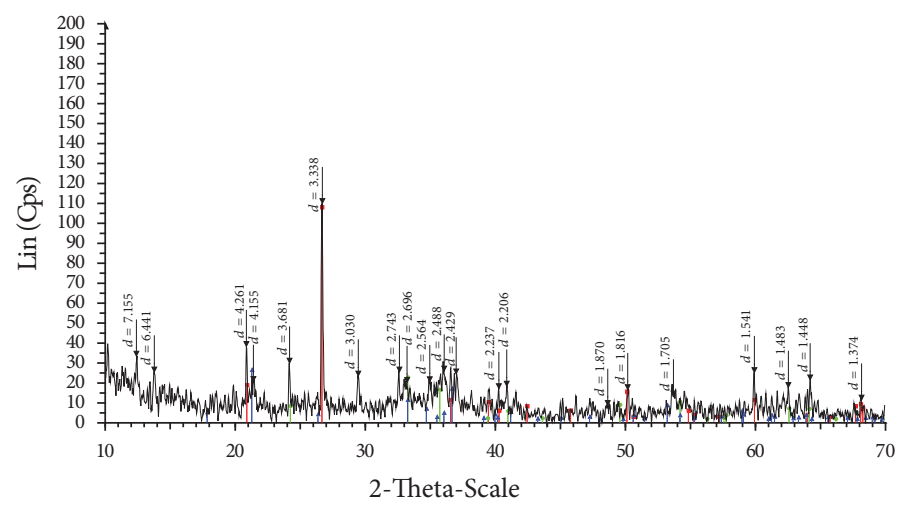

FIGURE 1: The XRD pattern of raw laterite.

Potentiometric method was used to determine $\mathrm{pH}$ of all solutions. The method was carried out using a HI 2215 Hanna Instruments $\mathrm{pH}$ meter by a glass combination electrode. We use three standard buffers (Hanna) to calibrate the electrode before measuring $\mathrm{pH}$ of solutions. All measurements were carried out at $25 \pm 2^{\circ} \mathrm{C}$.

2.4. Characterization Methods. The chemical compositions of laterite were examined by inductively coupled plasma mass spectrometer (ICP-MS Elan 9000, Perkin Elmer, USA) and total carbon analyzer using a TOC $\mathrm{V}_{\mathrm{CPH}}$ (Shimadzu, Japan).

$\mathrm{X}$-ray diffraction (XRD) was collected on a Bruker D8 Advance X-ray diffractometer, $\mathrm{CuK} \alpha$ radiation $(\lambda=$ $0.1549 \mathrm{~nm}$ ). Intensity for the diffraction peaks was recorded in the $10^{\circ}-70^{\circ}(2 \theta)$ range with a step size of $0.03^{\circ}$.

To evaluate functional groups of laterite and to confirm surface modification of laterite after $\mathrm{Cu}^{2+}$ adsorption, Fourier transform infrared spectroscopy was performed with an Affinity-1S (Shimadzu, Japan). The FT-IR spectra were obtained under at the same conditions: $25^{\circ} \mathrm{C}$, atmospheric pressure, and resolution of $4 \mathrm{~cm}^{-1}$.

\section{Modeling by General Isotherm Equation}

The obtained isotherms were fitted by a general isotherm equation. The equation was derived by assuming that two adsorption steps can occur at the solid-liquid interface [32].

The general isotherm equation is

$$
\Gamma=\frac{\Gamma_{\infty} k_{1} C\left(1 / n+k_{2} C^{n-1}\right)}{1+k_{1} C\left(1+k_{2} C^{n-1}\right)},
$$

where $\Gamma$ is amount of $\mathrm{Cu}^{2+}$ adsorbed; $\Gamma_{\infty}$ is the maximum adsorption amount; $k_{1}$ and $k_{2}$ are equilibrium constants for the first layer adsorption and clusters of $n$ molecules or multilayer adsorption. $C$ denotes the equilibrium concentration of $\mathrm{Cu}^{2+}$ in solution.

The selected fitting parameters were described in our previously published papers [35-37].
TABLE 1: The chemical composition of raw laterite.

\begin{tabular}{lc}
\hline Content (\%) & Value \\
\hline $\mathrm{Al}_{2} \mathrm{O}_{3}$ & 15.0 \\
$\mathrm{Fe}_{2} \mathrm{O}_{3}$ & 40.1 \\
$\mathrm{SiO}_{2}$ & 33.2 \\
$\mathrm{MnO}_{2}$ & 0.7 \\
$\mathrm{P}_{2} \mathrm{O}_{5}$ & 0.5 \\
$\mathrm{Na}_{2} \mathrm{O}$, & \\
$\mathrm{K}_{2} \mathrm{O}$, & $\sim 0.8$ \\
$\mathrm{CaO}$ & \\
$\mathrm{C}$ & 0.7 \\
\hline
\end{tabular}

\section{Results and Discussion}

\subsection{Characterization of Laterite}

4.1.1. Characterization of Raw Laterite. Table 1 shows the chemical compositions of raw laterite material. The inorganic components were determined by ICP-MS while carbon content was measured by TC. The results in Table 1 indicate that the main chemical compositions of laterite are metal oxides in which $\mathrm{Fe}_{2} \mathrm{O}_{3}, \mathrm{SiO}_{2}$, and $\mathrm{Al}_{2} \mathrm{O}_{3}$ are dominated. The composition of laterite used in the present study is similar to the published papers $[45,46]$.

The XRD pattern of laterite is represented in Figure 1. The predominated morphologies were found as quartz $\left(\mathrm{SiO}_{2}\right)$, hematite $\left(\mathrm{Fe}_{2} \mathrm{O}_{3}\right)$, and goethite $(\mathrm{FeO}(\mathrm{OH}))$. The peaks at $2 \theta=45,66$ indicated $\mathrm{Al}_{2} \mathrm{O}_{3}$ with very low intensity. The mineralogical phases of laterite used in this study is close to laterite used in other researches $[5,45]$.

Figure 2 indicates the FT-IR spectra of laterite without any modification. As can be seen in Figure 2, the band at 3622.32 and 3406.29 was assigned to - $\mathrm{OH}$ group of $\mathrm{Si}$ and $\mathrm{Al}$. Another band at 1645.28 was assigned to inner layer water molecules $[5,45]$. The bands at 1031.92, 1036.84, 912.33, and 796.60 appeared in the spectra because of the presence of $\mathrm{Si}-$ $\mathrm{O}-\mathrm{Fe}, \mathrm{Al}-\mathrm{OH}, \mathrm{Fe}-\mathrm{OH}$ vibrations. The $\mathrm{Fe}-\mathrm{O}$ bonds stretching at 534.28 and 464.84 were also obtained due to the presence of hematite in structure of laterite. The results of FT-IR are in good agreement with ICP-MS and XRD given above. 


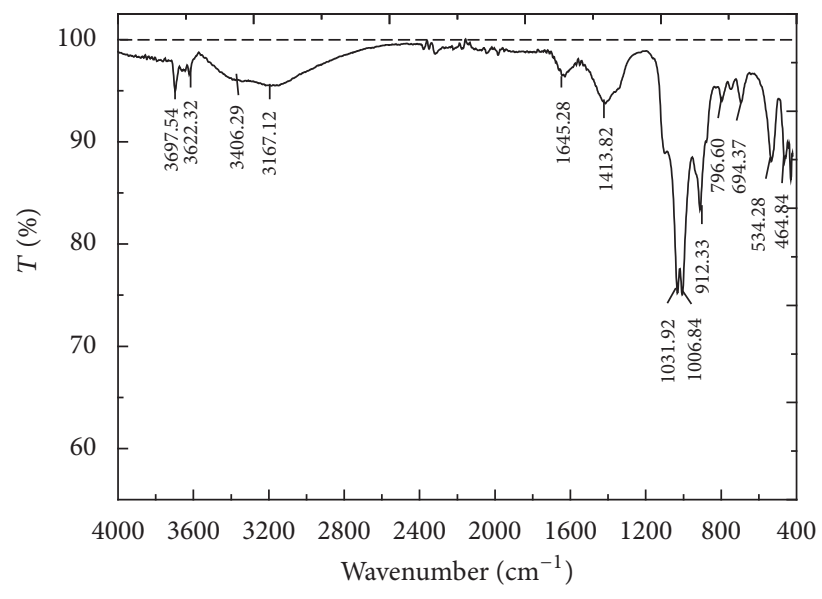

FIgURE 2: The FT-IR spectra of raw laterite.

4.1.2. Characterization of Laterite after SDS Preadsorption and Copper Adsorption. Anionic surfactant sodium dodecyl sulfate (SDS) with a concentration of $0.01 \mathrm{M}$ (higher than critical micelle concentration, CMC) was used to modify the surface of laterite in $0.01 \mathrm{M} \mathrm{NaCl}$ ( $\mathrm{pH}$ 5). In order to evaluate the change in mineral phase and surface modification and of laterite after preadsorption of SDS (SML) and sequential adsorption of $\mathrm{Cu}^{2+}$ with initial concentration of $100 \mathrm{ppm}$ in $10 \mathrm{mM} \mathrm{NaCl}(\mathrm{pH} 5)$, the XRD and FT-IR techniques are also used.

Figures 3(a) and 3(b) show that the morphologies still contain quartz $\left(\mathrm{SiO}_{2}\right)$, hematite $\left(\mathrm{Fe}_{2} \mathrm{O}_{3}\right)$, and goethite $(\mathrm{FeO}(\mathrm{OH}))$. These are similar to raw laterite, demonstrating that the structure of laterite does not change after adsorption SDS and adsorption of $\mathrm{Cu}^{2+}$. However, the intensity of special peaks assigned for each mineral phase was changed. The intensity of specific peak for $\mathrm{SiO}_{2}$ is enhanced while the others of $\mathrm{Fe}_{2} \mathrm{O}_{3}$ and $\mathrm{FeO}(\mathrm{OH})$ are reduced after preadsorption of SDS (Figure 3(a)) compared with original laterite. SDS is an anionic surfactant that can easily attract positive mineral $\left(\mathrm{Fe}_{2} \mathrm{O}_{3}\right.$ and $\left.\mathrm{FeO}(\mathrm{OH})\right)$ than negative one of $\mathrm{SiO}_{2}$. For the case of laterite after consequential adsorption of cation $\mathrm{Cu}^{2+}$, the peak indicated for $\mathrm{SiO}_{2}$ decreased dramatically while the others for $\mathrm{Fe}_{2} \mathrm{O}_{3}$ and $\mathrm{FeO}(\mathrm{OH})$ slightly increased [5, 27].

Figure 4 shows that FT-IR spectra of modified laterite by preadsorption of SDS are similar to the raw one (Figure $4(\mathrm{a})$ ). In additive, the relative intensity of asymmetrical and symmetrical stretching of $-\mathrm{CH}_{2}-$ presented at 2926.01 and $2854.65 \mathrm{~cm}^{-1}$ decreases dramatically in the spectra of SML while these peaks appear with very high intensity in spectra of SDS powder (data not shown). This confirms that the hydrophobic interaction can work on the surface of laterite. In addition, the characteristic peaks of $\mathrm{SO}_{4}{ }^{2-}$ at about $1247 \mathrm{~cm}^{-1}$ and $1218 \mathrm{~cm}^{-1}$ appear very strong in spectra of SDS while all bands disappear in the spectra of SML. It is demonstrated that SDS has sulfate head groups in contact with the surface of laterite via the electrostatic attraction at the current salt concentration $(10 \mathrm{mM} \mathrm{NaCl})$. In other words, the modification of laterite was successful due to the presence of bilayer and/or admicelles on the surface of laterite [36].
As can be seen in Figure 4(b), the band at 3442.94 assigned to $-\mathrm{OH}$ is very big due to the hydroxo complex of $\mathrm{Cu}(\mathrm{II})$. The bands at 1031.92, 1036.84, and 912.33 that appeared in the spectra of raw laterite are shifted to lower wavenumber at $1029.99,1004.91$, and 910.40 because the surface of laterite is changed. In addition, the peaks of $-\mathrm{CH}_{2}-$ present at 2926.01 and $2854.65 \mathrm{~cm}^{-1}$ of SML could not be seen in the spectra of SML after $\mathrm{Cu}^{2+}$ adsorption. These results suggest the adsorption of copper molecules onto SML via electrostatic attraction and nonelectrostatic interactions between $\mathrm{Cu}^{2+}$ and organic compounds in laterite.

4.2. Surface Modification of Laterite by SDS. Anionic surfactant SDS with a concentration of $0.01 \mathrm{M}$ was used to modify the surface of laterite in $0.01 \mathrm{M} \mathrm{NaCl}(\mathrm{pH}$ ). The obtained adsorption capacity of SDS on laterite (with solid-liquid ratio $200 \mathrm{mg} / \mathrm{mL}$ ) is $0.01 \mathrm{mmol} / \mathrm{g}$. Although the adsorption SDS on laterite is small, the loading implies the presence of bilayer and/or admicelles of SDS [36]. As a result, the surface charge of laterite is negative which can enhance adsorption of cationic heavy metal $\mathrm{Cu}^{2+}$. Figure 5 indicates that the removal efficiency of $\mathrm{Cu}^{2+}$ in $1 \mathrm{mM} \mathrm{NaCl}(\mathrm{pH}$ 5) with initial concentration of $10 \mathrm{ppm}$ increases from $61.6 \%$ to $89.5 \%$ after the surface modification of laterite by SDS.

Typical concentration of $\mathrm{Cu}(\mathrm{II})$ in wastewater and surface water is quite low. The limited concentration according to national technical regulation on water quality of Vietnam is equal to $1 \mathrm{mg} / \mathrm{L}$ for class B (low quality water). It should be noted that when the concentration of $\mathrm{Cu}$ (II) in aqueous solution is less than $2.5 \mathrm{mg} / \mathrm{L}$ the removal efficiency of copper through adsorption using SML is approximately 99\%. Furthermore, the maximum contaminant level (MCL) standard according to USEPA for $\mathrm{Cu}$ is $0.25 \mathrm{mg} / \mathrm{L}$. It implies that the $\mathrm{SML}$ is a promising material to remove $\mathrm{Cu}$ (II) from aqueous solutions.

Effective parameters on adsorptive removal of copper ion by using SML are systematically studied, as given below.

\subsection{Adsorptive Removal of Copper Ion by Using Surfactant Modified Laterite}

4.3.1. Effect of $p H$. Solution $\mathrm{pH}$ plays an important role in the adsorption of copper ion onto surfactant modified laterite (SML) because it can affect the surface charge of SML and charging behavior of chemical speciation of copper. At $\mathrm{pH}>7$, the high precipitation of $\mathrm{Cu}^{2+}$ can take place which influences the concentration of $\mathrm{Cu}^{2+}$ in solution. The effect of initial $\mathrm{pH}$ on the adsorption of $\mathrm{Cu}^{2+}$ by SML was investigated in the $\mathrm{pH}$ range of 3-7 in $1 \mathrm{mM} \mathrm{NaCl}$ (Figure 6). This implies that the negatively charged SML surface can easily attract $\mathrm{Cu}^{2+}$ by electrostatic attraction.

As can be seen in Figure 6, the removal of $\mathrm{Cu}^{2+}$ using SML increases with increasing solution $\mathrm{pH}$ from $\mathrm{pH} 4$ to $\mathrm{pH}$ 6 because of the competition between $\mathrm{H}^{+}$(at low $\mathrm{pH}$ ) and cation $\mathrm{Cu}^{2+}$ on the surface of SML. However, the desorption of SDS is increased at $\mathrm{pH}>7$ so that the removal efficiency of $\mathrm{Cu}^{2+}$ decreases. Thus, optimum $\mathrm{pH}$ for removal of $\mathrm{Cu}^{2+}$ by $\mathrm{SML}$ is $\mathrm{pH} 6$ which agrees well with optimum $\mathrm{pH}$ in the 


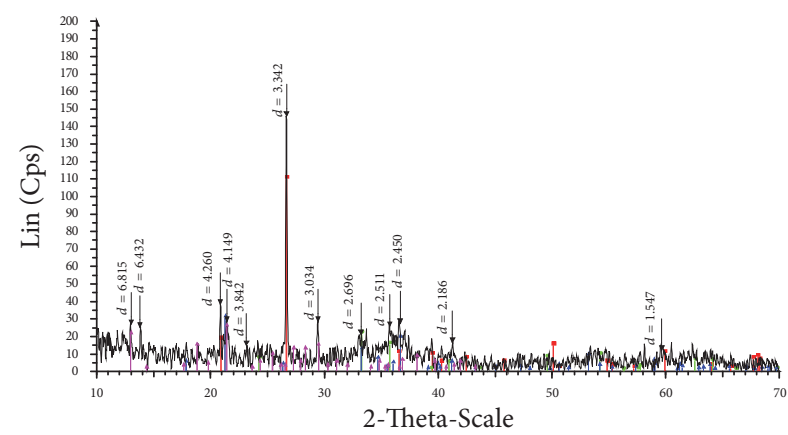

(a)

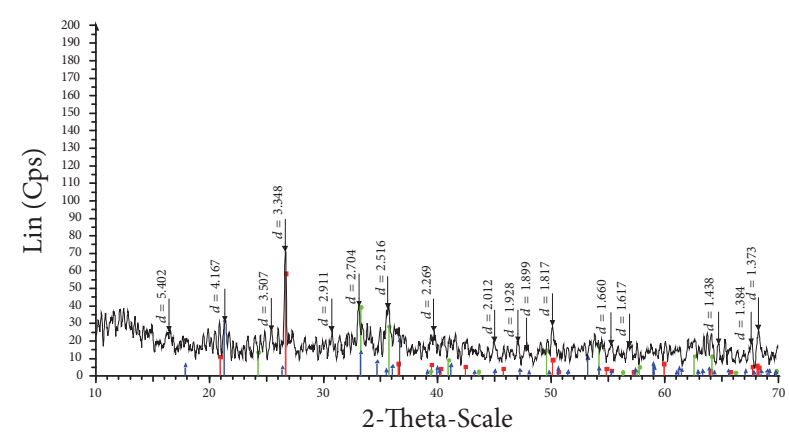

(b)

FIGURE 3: The XRD patterns of laterite after preadsorption of SDS (a) and after sequential adsorption of $\mathrm{Cu}^{2+}(\mathrm{b})$.

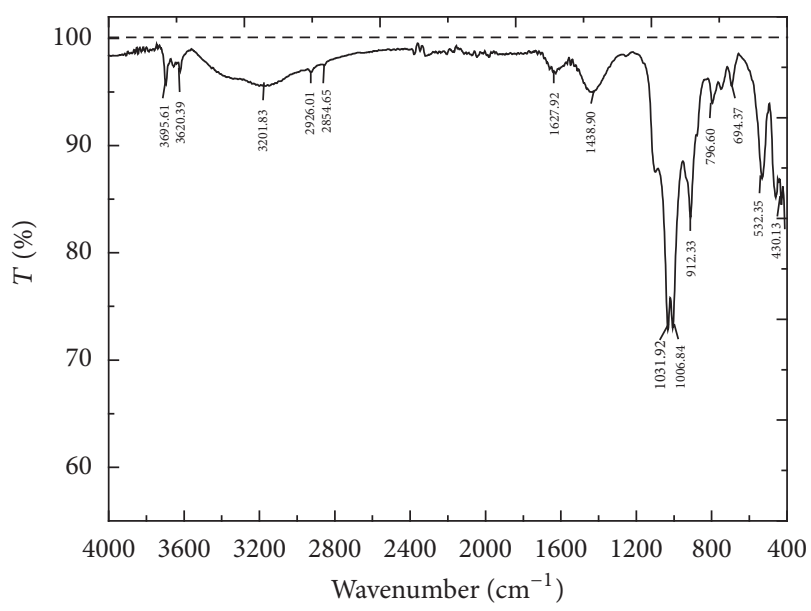

(a)

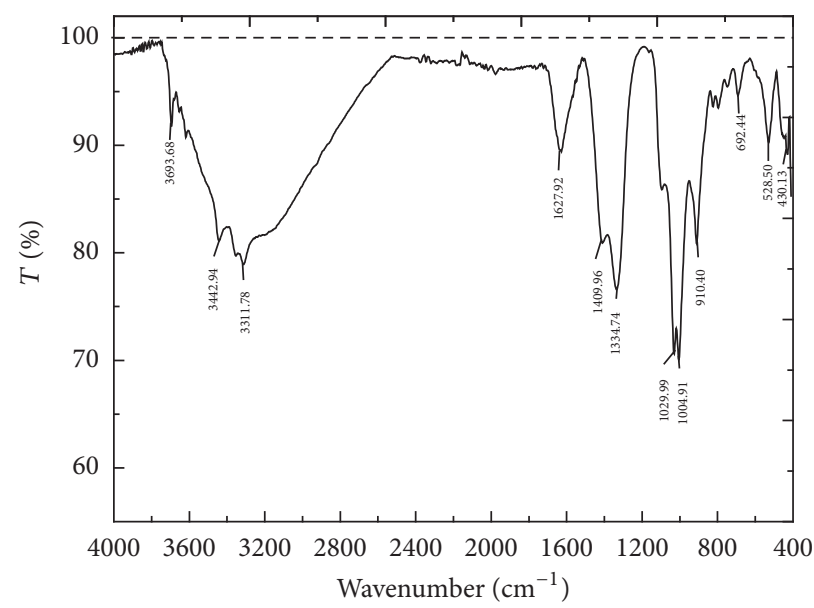

(b)

FIGURE 4: The FT-IR spectra of laterite after preadsorption of SDS (a) and after sequential adsorption of $\mathrm{Cu}^{2+}(\mathrm{b})$.

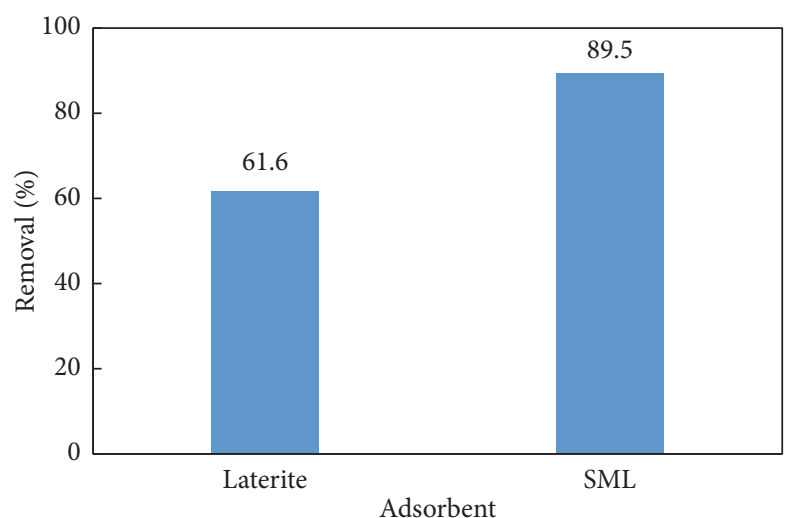

FIGURE 5: The removal of $\mathrm{Cu}^{2+}$ at the initial concentration of $10 \mathrm{ppm}$ in $1 \mathrm{mM} \mathrm{NaCl}(\mathrm{pH} 5)$ using laterite and surfactant modified laterite (SML).

case of adsorption heavy metal ions on surfactant modified alumina (SMA) [2, 3]. However, alumina is much more expensive compared with laterite so SML is more suitable than SMA for removing heavy metal ions in developing countries.

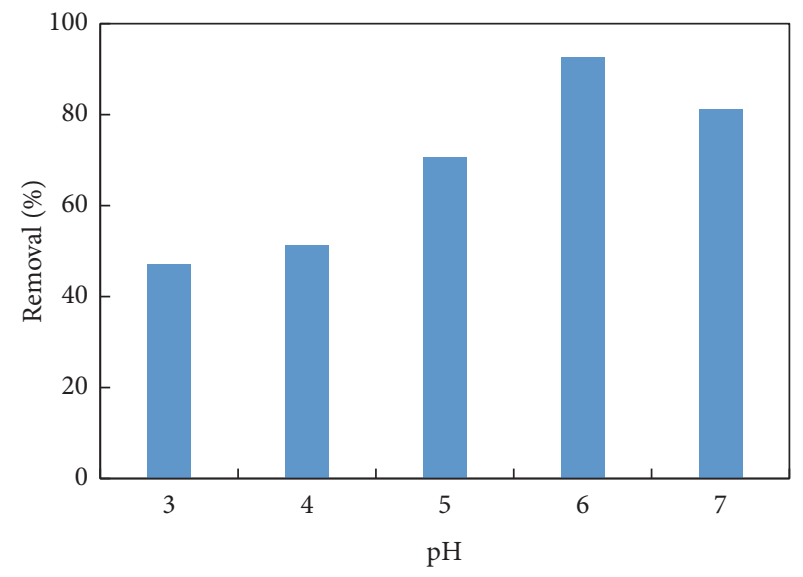

FIGURE 6: The removal of $\mathrm{Cu}^{2+}$ by surfactant modified laterite (SML) as a function of $\mathrm{pH}\left(\mathrm{Ci}\left(\mathrm{Cu}^{2+}\right)=10 \mathrm{ppm}\right.$; contact time $90 \mathrm{~min}$; adsorbent dosage $5 \mathrm{mg} / \mathrm{mL} ; 1 \mathrm{mM} \mathrm{NaCl})$.

The point of zero charge of laterite is about $7.4[45,46]$, meaning that at $\mathrm{pH}<7.4$ laterite has positive charge, since surface modification of laterite with SDS was conducted at $\mathrm{pH}$ 


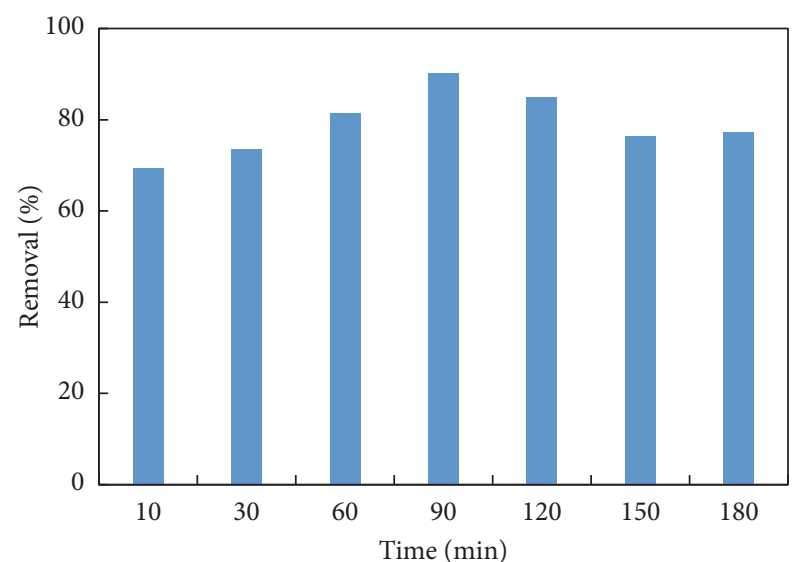

Figure 7: The removal of $\mathrm{Cu}^{2+}$ by SML at different contact time ( $\mathrm{Ci}$ $\left(\mathrm{Cu}^{2+}\right)=10$ ppm; $\mathrm{pH}$ 6; adsorbent dosage $\left.5 \mathrm{mg} / \mathrm{mL} ; 1 \mathrm{mM} \mathrm{NaCl}\right)$.

4.0 to promote preadsorption of SDS on laterite surface. After preadsorption of SDS, the concomitant of proton occurred so $\mathrm{pH}$ of solution increased around 0.6 units (from $\mathrm{pH} 5.0$ to 5.6). This trend is similar to the case of SDS adsorption on $\mathrm{Al}_{2} \mathrm{O}_{3}$ [36]. However, net surface charge of SML is negative which enhances adsorption of $\mathrm{Cu}^{2+}$ significantly. After copper adsorption, $\mathrm{pH}$ of solutions decreased (from 5.0 to 4.7), demonstrating that adsorption of cation $\mathrm{Cu}^{2+}$ induces the desorption of SDS with proton into solution.

4.3.2. Effect of Contact Time. Contact time affects the completeness of adsorption equilibration. The effect of contact time on the adsorptive removal of $\mathrm{Cu}^{2+}$ by using SML is presented in Figure 7. Figure 7 shows the removal efficiency of $\mathrm{Cu}^{2+}$ from aqueous solution by using SML growing with time from $10 \mathrm{~min}$ to $180 \mathrm{~min}$. It is suggested that adsorption reaches equilibrium at $90 \mathrm{~min}$. After $180 \mathrm{~min}$, the removal decreases because high concentration of $\mathrm{Na}^{+}$in $\mathrm{NaCl}$ background can displace $\mathrm{Cu}^{2+}$. The equilibrium adsorption in this study is longer than the case of adsorptive removal of $\mathrm{Cu}^{2+}$ by natural kaolin clay (only $30 \mathrm{~min}$ ) and the removal of $\mathrm{Cu}^{2+}$ by goethite mineral $(60 \mathrm{~min})[47,48]$. Nevertheless, $90 \mathrm{~min}$ is acceptable and is selected as the optimum contact time for removal of $\mathrm{Cu}^{2+}$ by using SML in $1 \mathrm{mM} \mathrm{NaCl}(\mathrm{pH} 6)$.

4.3.3. Effect of Adsorbent Dosage. The adsorbent dosage has a significant effect on the adsorption process because it can influence the total surface area of adsorbent and number of binding site. The amount of SML was varied from 0.05 to $6.0 \mathrm{~g}$ of adsorbent that corresponded from 1.0 to $12 \mathrm{mg} / \mathrm{mL}$ (Figure 8).

Figure 8 reveals that the removal of $\mathrm{Cu}^{2+}$ by SML increases with increasing adsorbent dosage from 1 to $12 \mathrm{mg} / \mathrm{mL}$. It may be explained by the increased large number of available binding sites for adsorption or increased net specific surface area with an increase of dosage [49]. However, an increase in adsorbent causes the increase of the adsorption capacity; then the adsorption capacity decreases due to the aggregation of colloidal particles at high adsorbent dosage

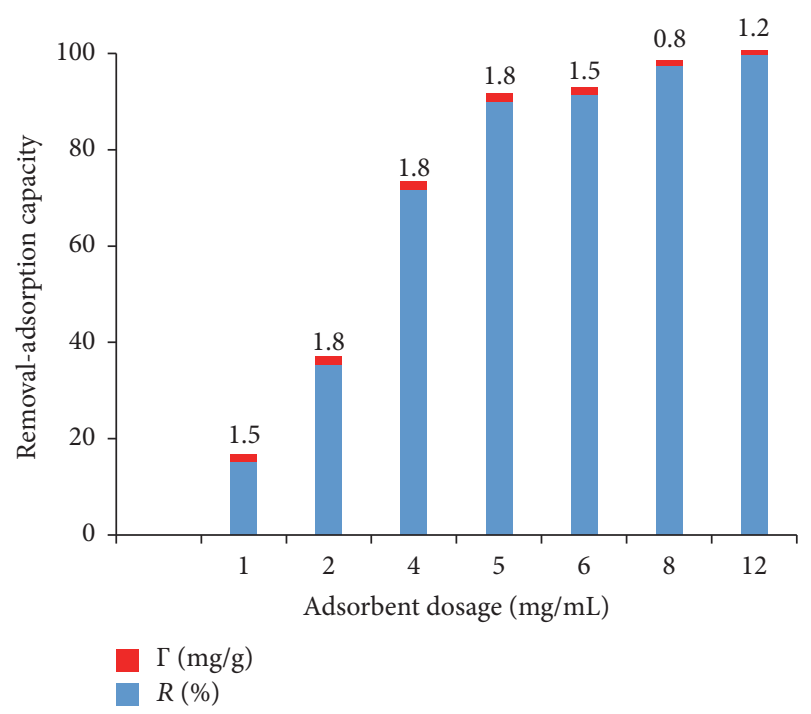

FIGURE 8: Removal $(R)$ and adsorption capacity $(\Gamma)$ of $\mathrm{Cu}^{2+}$ by SML as a function of adsorbent dosage $\left(\mathrm{Ci}\left(\mathrm{Cu}^{2+}\right)=10 \mathrm{ppm}\right.$; $\mathrm{pH}$ 6; contact time $90 \mathrm{~min} ; 1 \mathrm{mM} \mathrm{NaCl}$ ).

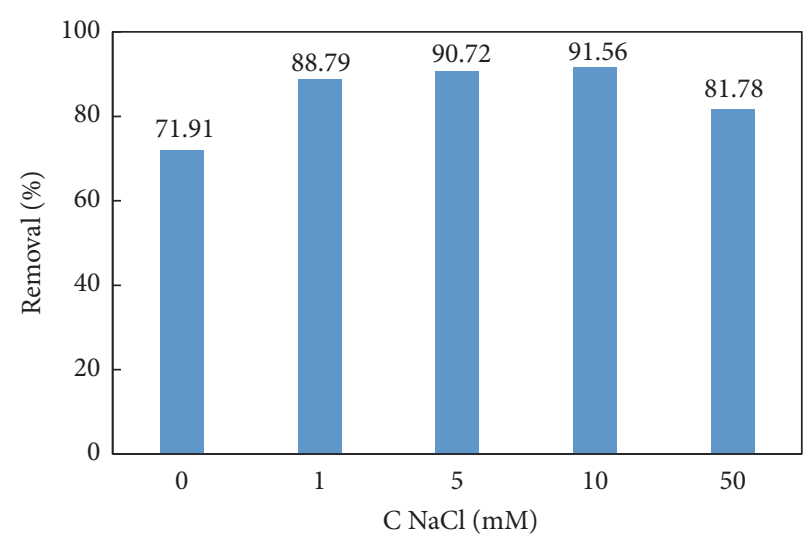

Figure 9: The removal of $\mathrm{Cu}^{2+}$ by $\mathrm{SML}$ at different $\mathrm{NaCl}$ concentrations $\left(\mathrm{Ci}\left(\mathrm{Cu}^{2+}\right)=10 \mathrm{ppm}\right.$; $\mathrm{pH}$ 6; contact time $90 \mathrm{~min}$; adsorbent dosage $5 \mathrm{mg} / \mathrm{mL})$.

[50]. Optimum adsorbent dosage is found to be $5 \mathrm{mg} / \mathrm{mL}$ and is fixed for the remaining studies.

4.3.4. Effect of Ionic Strength. Ionic strength affects electrostatic attraction between ionic adsorbates and charged surface adsorbent. For adsorption of $\mathrm{Cu}^{2+}$ onto SML, ionic strength also induces a change of existence of SDS molecules on laterite surface. As can be seen in Figure 9, the removal efficiency is lowest in the absence of salt, demonstrating that the electrostatic interaction causes adsorption. Furthermore, adsorption at $50 \mathrm{mM} \mathrm{NaCl}$ concentration is lower than that at $10 \mathrm{mM}$. This result can be explained by desorption of SDS at high salt concentration. Desorption of SDS is enhanced with increasing $\mathrm{NaCl}$ concentration from 10 to $50 \mathrm{mM}$. When increasing salt, the concentration of $\mathrm{Cl}^{-}$is high so the removal is decreased. However, the removal increases with an increase of $\mathrm{NaCl}$ concentration from 1 to $10 \mathrm{mM}$, suggesting that not 


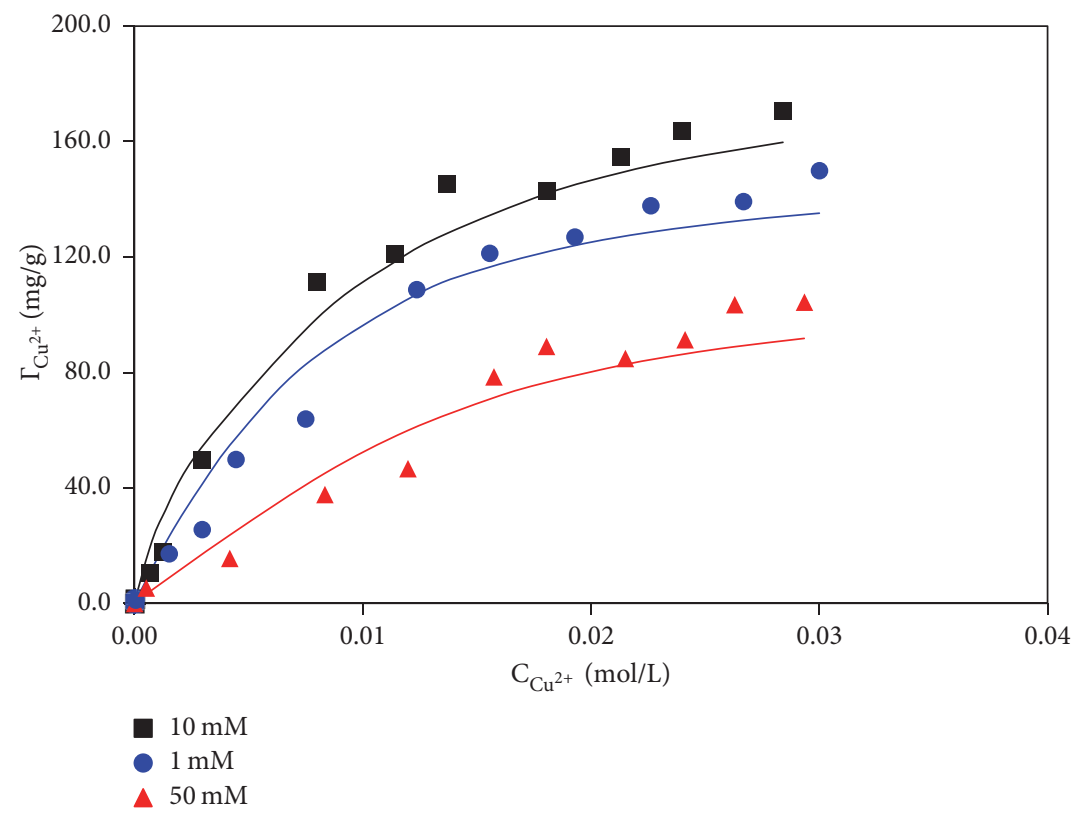

FIGURE 10: Adsorption isotherms of $\mathrm{Cu}^{2+}$ onto SDS modified laterite (SML) as a function of equilibrium concentration of $\mathrm{Cu}^{2+}$ at different $\mathrm{NaCl}$ concentrations. Points are experimental data; solid lines are results of the 2-step adsorption model.

TABLE 2: The fit parameters for $\mathrm{Cu}^{2+}$ adsorption onto SML which are maximum adsorbed amount $\Gamma_{\infty, \mathrm{Cu}^{2+}}$, the equilibrium constants $k_{1, \mathrm{Cu}^{2+}}$ and $k_{2, \mathrm{Cu}^{2+}}$ for first layer adsorption and multilayer adsorption, respectively, and the number of cluster of $\mathrm{Cu}^{2+}$ ion $n_{\mathrm{Cu}^{2+}}$.

\begin{tabular}{|c|c|c|c|c|}
\hline $\begin{array}{l}\text { C salt } \\
(\mathrm{mM} \mathrm{NaCl})\end{array}$ & $\begin{array}{r}\Gamma_{\infty, \mathrm{Cu}^{2+}} \\
(\mathrm{mg} / \mathrm{g})\end{array}$ & $\begin{array}{l}\mathbf{k}_{1, \mathrm{Cu}^{2+}} \\
(\mathrm{g} / \mathrm{mg})\end{array}$ & $\begin{array}{c}k_{2, \mathrm{Cu}^{2+}} \\
(\mathrm{g} / \mathrm{mg})^{\mathrm{n}-1}\end{array}$ & $\mathbf{n}_{\mathrm{Cu}^{2+}}$ \\
\hline 1 & 150 & $3.0 \times 10^{2}$ & $8.0 \times 10^{2}$ & 2.4 \\
\hline 10 & 185 & $5.0 \times 10^{2}$ & $8.0 \times 10^{2}$ & 2.5 \\
\hline 50 & 110 & $1.5 \times 10^{2}$ & $7.5 \times 10^{2}$ & 2.5 \\
\hline
\end{tabular}

only electrostatic but also nonelectrostatic between $\mathrm{Cu}(\mathrm{II})$ and/or $\mathrm{Cu}$ (II) speciation and organic substances in laterite induces adsorption. The effect of salt concentration will be discussed in the adsorption isotherms section.

\subsection{Characteristics and Mechanisms of Copper Ion Adsorption Isotherms on SDS Modified Laterite}

4.4.1. Adsorption Isotherms of Copper Ion on SDS Modified Laterite by a Two-Step Adsorption Model. The effect of ionic strength on adsorption of copper ion on SDS modified laterite (SML) is clearly demonstrated in the isotherms (Figure 10). At $\mathrm{pH}$, the $\mathrm{Cu}^{2+}$ adsorption capacity increases with increasing $\mathrm{NaCl}$ from 1 to $10 \mathrm{mM}$. At higher salt concentration (from 10 to $50 \mathrm{mM}$ ), the adsorption capacity reduces with an increase of salt. The increase in salt concentration increases the number of cations $\mathrm{Na}^{+}$(counterions) on the negatively charged layer of SML, reducing the electrostatic effect of SML $\mathrm{Cu}^{2+}$ ion. It is quite different from the case of adsorption of copper ion on strawberry leaf powder [51] in which the effect of $\mathrm{Na}^{+}, \mathrm{K}^{+}, \mathrm{Mg}^{2+}$, and $\mathrm{Ca}^{2+}$ on the copper adsorption is not significant. In our case, the electrostatic attraction between the positive charge of $\mathrm{Cu}^{2+}$ ion and negative charge of SML is effectively screened by increasing $\mathrm{NaCl}$ concentrations from 10 to $50 \mathrm{mM}$. Nonelectrostatic interactions are more important in adsorption at low ionic strength (1 to $10 \mathrm{mM}$ $\mathrm{NaCl}$ ). These results agree well with the effect of ionic strength on the removal of copper ion using SML shown in previous section.

Figure 10 indicates that, at different salt concentrations, the experimental results can be represented well by the general isotherm equation (2) with the fitting parameters in Table 2 .

As shown in Table 2, increasing ionic strength from 1 to $10 \mathrm{mM}$ causes an increase in $\mathbf{k}_{1, \mathrm{Cu}^{2+}}$ but a decrease in $\mathbf{k}_{1, \mathrm{Cu}^{2+}}$ when increasing salt from 10 to $50 \mathrm{mM}$. It is noted that the changes in $k_{2, \mathrm{Cu}^{2+}}$ and the number of $\mathrm{Cu}^{2+}$ clusters are not significant $\left(k_{2, \mathrm{NH}_{4}^{+}} \approx 8.0 \times 10^{2}\right.$ and $\left.\mathbf{n}_{\mathrm{Cu}^{2+}} \approx 2.5\right)$. The value of $\mathbf{k}_{1, \mathrm{Cu}^{2+}}$ is also related to the slope of isotherm. As a result, at high salt concentration, the slope is lower than that at low salt. It suggests that desorption of SDS from the bilayer of admicelles is enhanced by increasing salt concentration from 10 to $50 \mathrm{mM}$ while at low salt concentration the link between sulfate groups of SDS an $\mathrm{Cu}^{2+}$ is not strong as other interactions.

4.4.2. Adsorption Mechanisms and Advantages of Copper Ion onto SDS Modified Laterite. Adsorptive removal of copper 
TABLE 3: Adsorption capacity of $\mathrm{Cu}^{2+}$ on natural materials or modified natural materials and SML.

\begin{tabular}{lcc}
\hline Adsorbent & Adsorption capacity $(\mathrm{mg} / \mathrm{g})$ & References \\
\hline Zeolite, clinoptilolite & 1.64 & {$[12]$} \\
HCl-treated clay & 83.3 & {$[42]$} \\
Marine alga, Ecklonia maxima & 90 & {$[43]$} \\
Red paddy soil & 0.21 & {$[44]$} \\
SDS modified laterite & 185 & This study \\
\hline
\end{tabular}

ion $\left(\mathrm{Cu}^{2+}\right)$ is enhanced by using anionic surfactant, SDS modified laterite (SML). The effective conditions on adsorption of $\mathrm{Cu}^{2+}$ ion by SML were systematically studied in Section 4.3. The two-step model was established to describe the $\mathrm{Cu}^{2+}$ adsorption onto SML, suggesting that adsorption of $\mathrm{Cu}^{2+}$ could replace admicellar bilayers of SDS molecules on the laterite surface at high salt concentration. Adsorption of $\mathrm{Cu}^{2+}$ decreases with an increase of ionic strength at high salt concentration because desorption of SDS is enhanced by increasing salt concentration [35] which is in good agreement with discussion in Section 4.3.1. It is also represented by two-step adsorption model with decreasing $\mathbf{k}_{1, \mathrm{Cu}^{2+}}$ when increasing $\mathrm{NaCl}$ concentration from 10 to $50 \mathrm{mM}$. At low salt concentration, the main interactions inducing adsorption may be lateral, hydrogen bonding, surface complexation, and Van der Waals interactions between $\mathrm{Cu}^{2+}$ and organic substances in the laterite.

Adsorption mechanisms of $\mathrm{Cu}^{2+}$ ion on SML are also supported by the results of FT-IR spectra (see Section 4.1.2). The bands of $\mathrm{CH}_{2}-$ of SML did not occur after adsorption of $\mathrm{Cu}^{2+}$ in $10 \mathrm{mM} \mathrm{NaCl}$, suggesting that the adsorption of $\mathrm{Cu}^{2+}$ onto SML is mainly controlled by the electrostatic attraction between the negatively charged sulfate groups of bilayer admicelles and positive charge of $\mathrm{Cu}^{2+}$. It seems to be similar to the case of $\mathrm{Cu}^{2+}$ on natural kaolinite clays [48]. Nevertheless, at low ionic strength, the attraction between positive $\mathrm{Cu}^{2+}$ and negative SML is not so strong compared with other interactions. In this case, nonelectrostatic interactions between $\mathrm{Cu}^{2+}$ and/or speciation of $\mathrm{Cu}^{2+}$ with organic substances in laterite mainly contribute to adsorption.

Some published papers focused on sorption of $\mathrm{Cu}$ (II) onto different kinds of sorbents. Nevertheless, sorption of $\mathrm{Cu}$ (II) onto SML has not been reported. Furthermore, SML used in the present study has very high adsorption capacity $(185 \mathrm{mg} / \mathrm{g})$ compared with other natural sorbents or modified natural materials (Table 3). It demonstrates that SML is novel material for removal of $\mathrm{Cu}$ (II) from aqueous solution.

\section{Conclusions}

For the first time, we investigated adsorption characteristics of copper ion $\left(\mathrm{Cu}^{2+}\right)$ on sodium dodecyl sulfate (SDS) surfactant modified laterite (SML) in aqueous solution. The adsorption experiments were quantified by flame atomic absorption spectrometry (F-AAS). The raw laterite, laterite after preadsorption of SDS, and sequential adsorption of $\mathrm{Cu}^{2+}$ were characterized by X-ray diffraction (XRD) and Fourier transform infrared spectroscopy (FT-IR). The optimum conditions for adsorptive removal of $\mathrm{Cu}^{2+}$ using SML were found as $\mathrm{pH} \mathrm{6,} \mathrm{contact} \mathrm{time} 90 \mathrm{~min}$, adsorbent dosage $5 \mathrm{mg} / \mathrm{mL}$, and ionic strength $10 \mathrm{mM} \mathrm{NaCl}$. Adsorption isotherms of $\mathrm{Cu}^{2+}$ on $\mathrm{SML}$ at different $\mathrm{NaCl}$ concentrations were fitted well by a two-step adsorption model. The adsorption of $\mathrm{Cu}^{2+}$ on SML decreased with an increase of $\mathrm{NaCl}$ concentration due to the enhancement of SDS desorption with increasing salt concentration but at low $\mathrm{NaCl}$ concentrations (1 to $10 \mathrm{mM}$ ), adsorption $\mathrm{Cu}^{2+}$ on SML increased with an increase of salt. Adsorption mechanisms of $\mathrm{Cu}^{2+}$ onto SML were mainly controlled by electrostatic attraction between the positive charge of $\mathrm{Cu}^{2+}$ and the negatively charged layer SML at high ionic strength while at low ionic strength nonelectrostatic interactions between $\mathrm{Cu}^{2+}$ and organic compounds in laterite induced adsorption. The SML was demonstrated as a novel adsorbent to remove $\mathrm{Cu}^{2+}$ from aqueous solutions.

\section{Competing Interests}

The authors declare that they have no competing interests.

\section{Acknowledgments}

This research is funded by the Vietnam National University, Hanoi (VNU), under Project no. QG.16.12.

\section{References}

[1] V. K. Gupta, I. Ali, T. A. Saleh, A. Nayak, and S. Agarwal, "Chemical treatment technologies for waste-water recyclingan overview," RSC Advances, vol. 2, no. 16, pp. 6380-6388, 2012.

[2] M. U. Khobragade and A. Pal, "Adsorptive removal of Mn(II) from water and wastewater by surfactant-modified alumina," Desalination and Water Treatment, vol. 57, no. 6, pp. 2775-2786, 2016.

[3] M. U. Khobragade and A. Pal, "Fixed-bed column study on removal of $\mathrm{Mn}(\mathrm{II}), \mathrm{Ni}(\mathrm{II})$ and $\mathrm{Cu}(\mathrm{II})$ from aqueous solution by surfactant bilayer supported alumina," Separation Science and Technology (Philadelphia), vol. 51, no. 8, pp. 1287-1298, 2016.

[4] M. MacHida, B. Fotoohi, Y. Amamo, and L. Mercier, "Cadmium(II) and lead(II) adsorption onto hetero-atom functional mesoporous silica and activated carbon," Applied Surface Science, vol. 258, no. 19, pp. 7389-7394, 2012.

[5] S. Mitra, L. S. Thakur, V. K. Rathore, and P. Mondal, "Removal of $\mathrm{Pb}(\mathrm{II})$ and $\mathrm{Cr}(\mathrm{VI})$ by laterite soil from synthetic waste water: single and bi-component adsorption approach," Desalination and Water Treatment, vol. 57, no. 39, pp. 18406-18416, 2016. 
[6] B. Prélot, W. Janusz, F. Thomas et al., "Adsorption of cadmium ions at the electrolyte/silica interface I. Experimental study of surface properties," Applied Surface Science, vol. 196, no. 1-4, pp. 322-330, 2002.

[7] M. K. Sahu, S. Mandal, S. S. Dash, P. Badhai, and R. K. Patel, "Removal of $\mathrm{Pb}(\mathrm{II})$ from aqueous solution by acid activated red mud," Journal of Environmental Chemical Engineering, vol. 1, no. 4, pp. 1315-1324, 2013.

[8] S. E. Bailey, T. J. Olin, R. M. Bricka, and D. D. Adrian, "A review of potentially low-cost sorbents for heavy metals," Water Research, vol. 33, no. 11, pp. 2469-2479, 1999.

[9] H. B. Bradl, "Adsorption of heavy metal ions on soils and soils constituents," Journal of Colloid and Interface Science, vol. 277, no. 1, pp. 1-18, 2004.

[10] F. Fu and Q. Wang, "Removal of heavy metal ions from wastewaters: a review," Journal of Environmental Management, vol. 92, no. 3, pp. 407-418, 2011.

[11] A. Radian, D. Michaeli, C. Serban, R. Nechushtai, and Y. G. Mishael, "Bioactive apo-ferredoxin-polycation-clay composites for iron binding," Journal of Materials Chemistry, vol. 20, no. 21, pp. 4361-4365, 2010.

[12] S. Babel and T. A. Kurniawan, "Low-cost adsorbents for heavy metals uptake from contaminated water: a review," Journal of Hazardous Materials, vol. 97, no. 1-3, pp. 219-243, 2003.

[13] H.-P. Chao, C.-K. Lee, L.-C. Juang, and Y.-L. Han, "Sorption of organic compounds, oxyanions, and heavy metal ions on surfactant modified titanate nanotubes," Industrial and Engineering Chemistry Research, vol. 52, no. 29, pp. 9843-9850, 2013.

[14] C. Faur-Brasquet, Z. Reddad, K. Kadirvelu, and P. Le Cloirec, "Modeling the adsorption of metal ions $\left(\mathrm{Cu}^{2+}, \mathrm{Ni}^{2+}, \mathrm{Pb}^{2+}\right)$ onto ACCs using surface complexation models," Applied Surface Science, vol. 196, no. 1-4, pp. 356-365, 2002.

[15] M. Visa, C. Bogatu, and A. Duta, "Simultaneous adsorption of dyes and heavy metals from multicomponent solutions using fly ash," Applied Surface Science, vol. 256, no. 17, pp. 5486-5491, 2010.

[16] M. U. Khobragade and A. Pal, "Fixed-bed column study on removal of $\mathrm{Mn}(\mathrm{II}), \mathrm{Ni}(\mathrm{II})$ and $\mathrm{Cu}(\mathrm{II})$ from aqueous solution by surfactant bilayer supported alumina," Separation Science and Technology, vol. 51, no. 8, pp. 1287-1298, 2016.

[17] T. A. Saleh and V. K. Gupta, "Processing methods, characteristics and adsorption behavior of tire derived carbons: a review," Advances in Colloid and Interface Science, vol. 211, pp. 93-101, 2014.

[18] M. Ahmaruzzaman, "Industrial wastes as low-cost potential adsorbents for the treatment of wastewater laden with heavy metals," Advances in Colloid and Interface Science, vol. 166, no. 1-2, pp. 36-59, 2011.

[19] K. Z. Elwakeel, "Removal of $\mathrm{Cr}(\mathrm{VI})$ from alkaline aqueous solutions using chemically modified magnetic chitosan resins," Desalination, vol. 250, no. 1, pp. 105-112, 2010.

[20] K. Z. Elwakeel and E. Guibal, "Potential use of magnetic glycidyl methacrylate resin as a mercury sorbent: from basic study to the application to wastewater treatment," Journal of Environmental Chemical Engineering, vol. 4, no. 3, pp. 3632-3645, 2016.

[21] M. M. H. Khalil, K. Z. Al-Wakeel, S. S. A. E. Rehim, and H. A. E. Monem, "Efficient removal of ferric ions from aqueous medium by amine modified chitosan resins," Journal of Environmental Chemical Engineering, vol. 1, no. 3, pp. 566-573, 2013.

[22] M. Ozmen, K. Can, G. Arslan, A. Tor, Y. Cengeloglu, and M. Ersoz, "Adsorption of $\mathrm{Cu}(\mathrm{II})$ from aqueous solution by using modified $\mathrm{Fe}_{3} \mathrm{O}_{4}$ magnetic nanoparticles," Desalination, vol. 254, no. 1-3, pp. 162-169, 2010.

[23] W. Sun, K. Yin, and X. Yu, "Effect of natural aquatic colloids on $\mathrm{Cu}(\mathrm{II})$ and $\mathrm{Pb}(\mathrm{II})$ adsorption by $\mathrm{Al}_{2} \mathrm{O}_{3}$ nanoparticles," Chemical Engineering Journal, vol. 225, pp. 464-473, 2013.

[24] X. Sun, X. Huang, X.-P. Liao, and B. Shi, "Adsorptive removal of $\mathrm{Cu}$ (II) from aqueous solutions using collagen-tannin resin," Journal of Hazardous Materials, vol. 186, no. 2-3, pp. 1058-1063, 2011.

[25] M.-W. Wan, C.-C. Kan, B. D. Rogel, and M. L. P. Dalida, "Adsorption of copper (II) and lead (II) ions from aqueous solution on chitosan-coated sand," Carbohydrate Polymers, vol. 80, no. 3, pp. 891-899, 2010.

[26] M. Li, M.-Y. Li, C.-G. Feng, and Q.-X. Zeng, "Preparation and characterization of multi-carboxyl-functionalized silica gel for removal of $\mathrm{Cu}$ (II), Cd (II), $\mathrm{Ni}$ (II) and $\mathrm{Zn}$ (II) from aqueous solution," Applied Surface Science, vol. 314, pp. 1063-1069, 2014.

[27] A. Maiti, J. K. Basu, and S. De, "Development of a treated laterite for arsenic adsorption: effects of treatment parameters," Industrial and Engineering Chemistry Research, vol. 49, no. 10, pp. 4873-4886, 2010.

[28] M. Sarkar, A. Banerjee, P. P. Pramanick, and A. R. Sarkar, "Use of laterite for the removal of fluoride from contaminated drinking water," Journal of Colloid and Interface Science, vol. 302, no. 2, pp. 432-441, 2006.

[29] M. J. Rosen and J. T. Kunjappu, Surfactants and Interfacial Phenomena, John Wiley \& Sons, 2012.

[30] H. M. F. Freundlich, "Über die adsorption in lösungen," Zeitschrift für Physikalische Chemie, vol. 57, pp. 385-470, 1906.

[31] I. Langmuir, "The adsorption of gases on plane surfaces of glass, mica and platinum," The Journal of the American Chemical Society, vol. 40, no. 9, pp. 1361-1403, 1918.

[32] B.-Y. Zhu and T. Gu, "Surfactant adsorption at solid-liquid interfaces," Advances in Colloid and Interface Science, vol. 37, no. 1-2, pp. 1-32, 1991.

[33] I. Hoffmann, C. Oppel, U. Gernert, P. Barreleiro, W. von Rybinski, and M. Gradzielski, "Adsorption isotherms of cellulosebased polymers onto cotton fibers determined by means of a direct method of fluorescence spectroscopy," Langmuir, vol. 28, no. 20, pp. 7695-7703, 2012.

[34] R. S. Ndong and W. B. Russel, "Linear viscoelasticity of $\mathrm{ZrO}_{2}$ nanoparticle dispersions with associative polymers," Rheologica Acta, vol. 51, no. 9, pp. 771-782, 2012.

[35] T. D. Pham, M. Kobayashi, and Y. Adachi, "Adsorption of polyanion onto large alpha alumina beads with variably charged surface," Advances in Physical Chemistry, vol. 2014, Article ID 460942, 9 pages, 2014.

[36] T. D. Pham, M. Kobayashi, and Y. Adachi, "Adsorption of anionic surfactant sodium dodecyl sulfate onto alpha alumina with small surface area," Colloid and Polymer Science, vol. 293, no. 1, pp. 217-227, 2015.

[37] T. D. Pham, M. Kobayashi, and Y. Adachi, "Adsorption characteristics of anionic azo dye onto large $\alpha$-alumina beads," Colloid and Polymer Science, vol. 293, no. 7, pp. 1877-1886, 2015.

[38] A. Adak, M. Bandyopadhyay, and A. Pal, "Removal of crystal violet dye from wastewater by surfactant-modified alumina," Separation and Purification Technology, vol. 44, no. 2, pp. 139144, 2005.

[39] A. Adak, M. Bandyopadyay, and A. Pal, "Fixed bed column study for the removal of crystal violet (C. I. Basic Violet 3) dye from aquatic environment by surfactant-modified alumina," Dyes and Pigments, vol. 69, no. 3, pp. 245-251, 2006. 
[40] A. Adak, A. Pal, and M. Bandyopadhyay, "Removal of phenol from water environment by surfactant-modified alumina through adsolubilization," Colloids and Surfaces A: Physicochemical and Engineering Aspects, vol. 277, no. 1-3, pp. 63-68, 2006.

[41] A. K. Das, S. Saha, A. Pal, and S. K. Maji, "Surfactant-modified alumina: an efficient adsorbent for malachite green removal from water environment," Journal of Environmental Science and Health. Part A, vol. 44, no. 9, pp. 896-905, 2009.

[42] T. Vengris, R. Binkiene, and A. Sveikauskaite, "Nickel, copper and zinc removal from waste water by a modified clay sorbent," Applied Clay Science, vol. 18, no. 3-4, pp. 183-190, 2001.

[43] D. Feng and C. Aldrich, "Adsorption of heavy metals by biomaterials derived from the marine alga Ecklonia maxima," Hydrometallurgy, vol. 73, no. 1-2, pp. 1-10, 2004.

[44] B. Huang, Z. Li, J. Huang et al., "Adsorption characteristics of Cu and $\mathrm{Zn}$ onto various size fractions of aggregates from red paddy soil," Journal of Hazardous Materials, vol. 264, pp. 176-183, 2014.

[45] A. Maiti, J. K. Basu, and S. De, "Experimental and kinetic modeling of $\mathrm{As}(\mathrm{V})$ and $\mathrm{As}(\mathrm{III})$ adsorption on treated laterite using synthetic and contaminated groundwater: effects of phosphate, silicate and carbonate ions," Chemical Engineering Journal, vol. 191, pp. 1-12, 2012.

[46] A. Maiti, H. Sharma, J. K. Basu, and S. De, "Modeling of arsenic adsorption kinetics of synthetic and contaminated groundwater on natural laterite," Journal of Hazardous Materials, vol. 172, no. 2-3, pp. 928-934, 2009.

[47] A. Jaiswal, S. Banerjee, R. Mani, and M. C. Chattopadhyaya, "Synthesis, characterization and application of goethite mineral as an adsorbent," Journal of Environmental Chemical Engineering, vol. 1, no. 3, pp. 281-289, 2013.

[48] M.-Q. Jiang, X.-Y. Jin, X.-Q. Lu, and Z.-L. Chen, "Adsorption of $\mathrm{Pb}(\mathrm{II}), \mathrm{Cd}(\mathrm{II}), \mathrm{Ni}(\mathrm{II})$ and $\mathrm{Cu}(\mathrm{II})$ onto natural kaolinite clay," Desalination, vol. 252, no. 1-3, pp. 33-39, 2010.

[49] F. Mazloomi and M. Jalali, "Ammonium removal from aqueous solutions by natural Iranian zeolite in the presence of organic acids, cations and anions," Journal of Environmental Chemical Engineering, vol. 4, no. 2, pp. 1664-1673, 2016.

[50] J. K. Wolterink, L. K. Koopal, M. A. C. Stuart, and W. H. Van Riemsdijk, "Surface charge regulation upon polyelectrolyte adsorption, hematite, polystyrene sulfonate, surface charge regulation: theoretical calculations and hematite-poly(styrene sulfonate) system," Colloids and Surfaces A: Physicochemical and Engineering Aspects, vol. 291, no. 1-3, pp. 13-23, 2006.

[51] H. Liu, Y. Dong, H. Wang, and Y. Liu, "Ammonium adsorption from aqueous solutions by strawberry leaf powder: equilibrium, kinetics and effects of coexisting ions," Desalination, vol. 263, no. 1-3, pp. 70-75, 2010. 

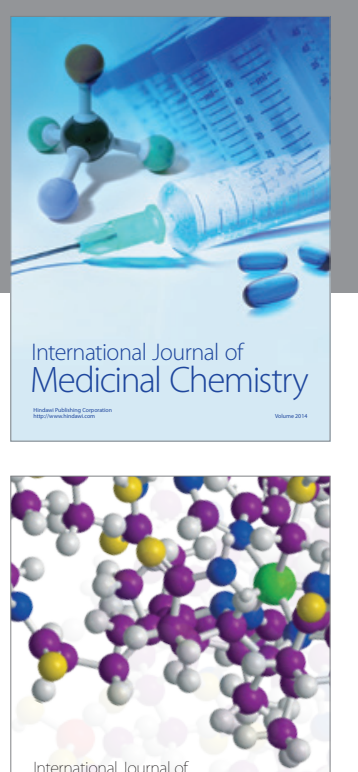

Carbohydrate Chemistry

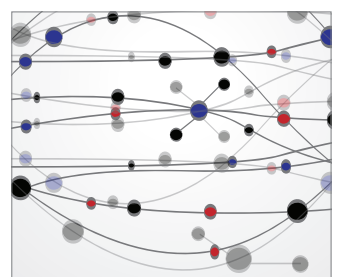

The Scientific World Journal
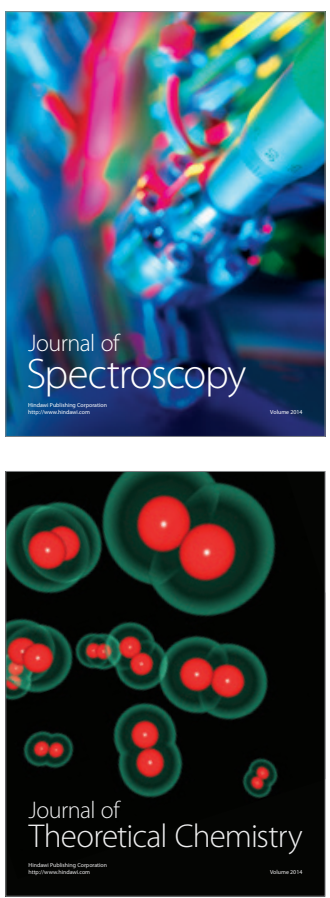
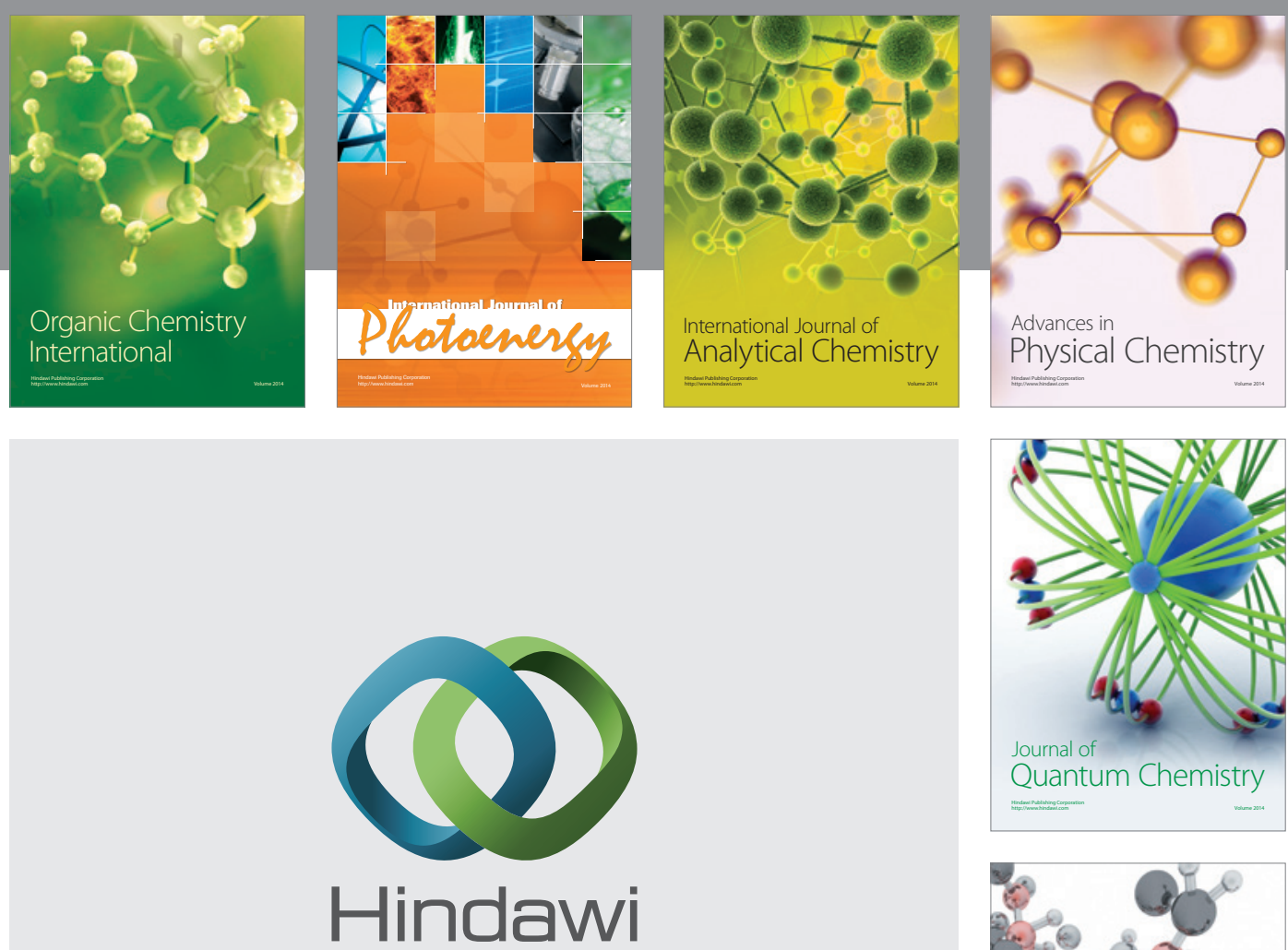

Submit your manuscripts at

https://www.hindawi.com

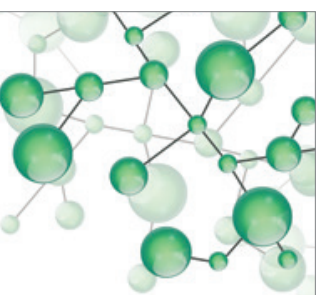

International Journal of

Inorganic Chemistry
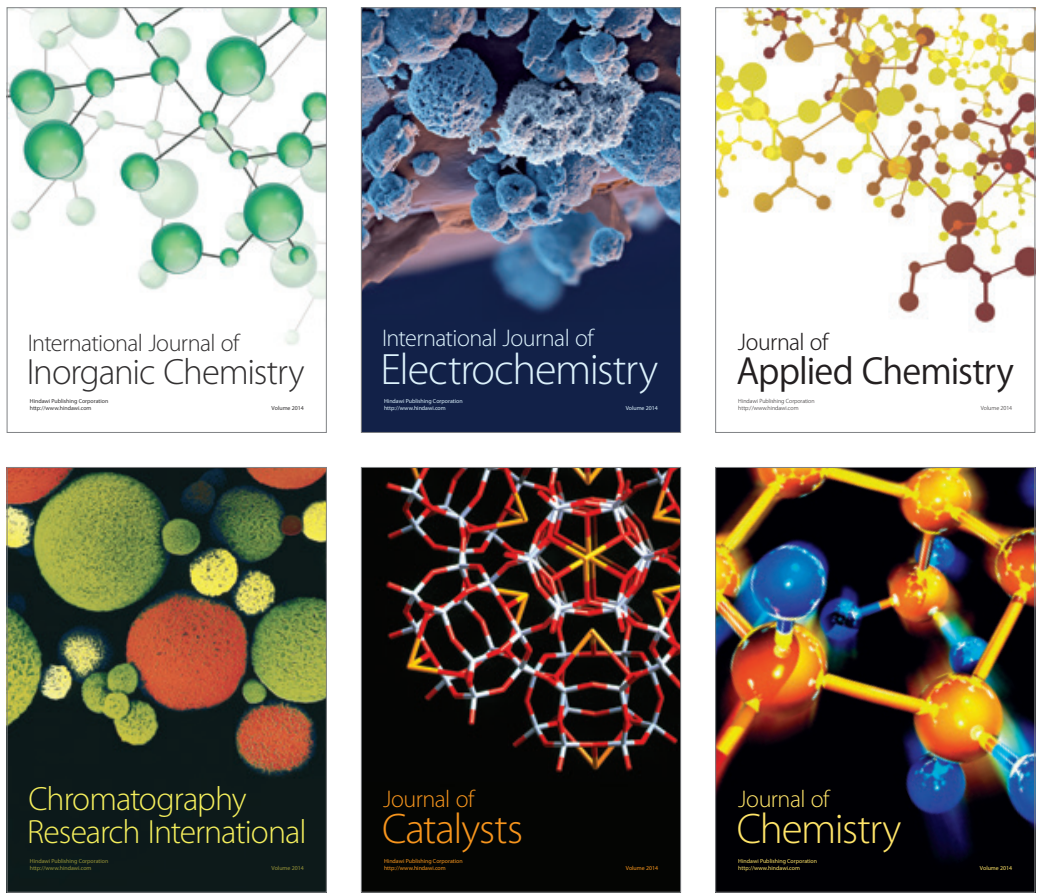

Journal of

Applied Chemistry
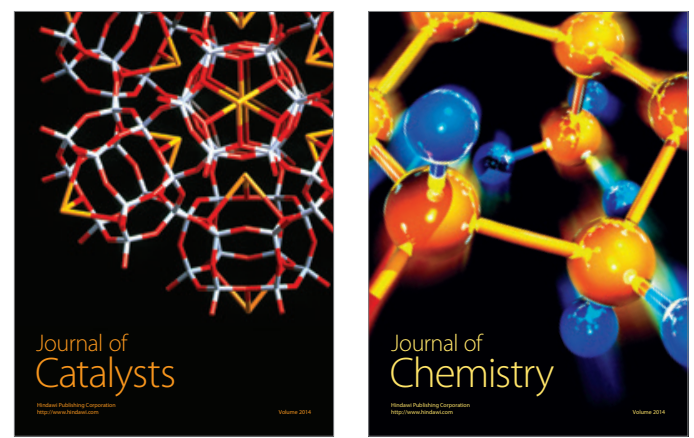
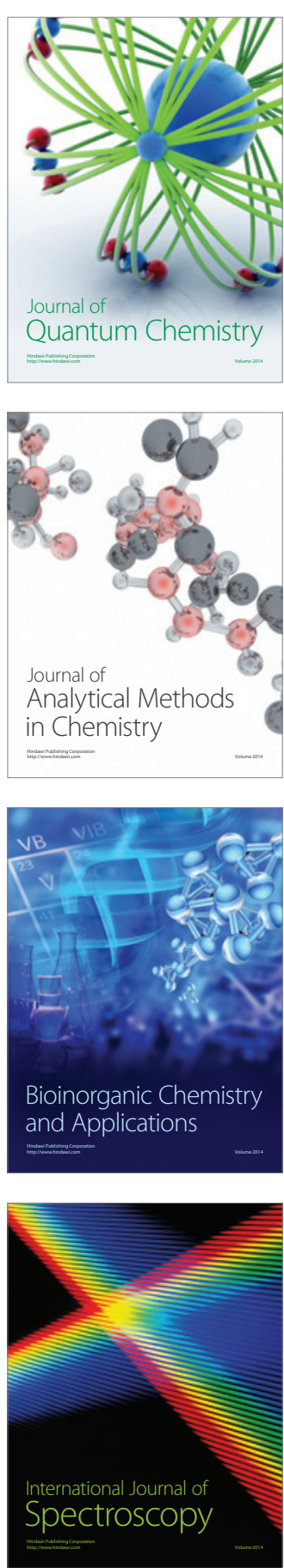